University of Nebraska - Lincoln

DigitalCommons@University of Nebraska - Lincoln

$1-2001$

\title{
Clinal variation in body size and sexual dimorphism in an Indian fruit bat, Cynopterus sphinx (Chiroptera: Pteropodidae)
}

Jay F. Storz

University of Nebraska - Lincoln, jstorz2@unl.edu

J. Balasingh

St. John's College, Palayamkottai, 627 002, India

Hari Bhat

National Institute of Virology, Pune, 411 001, India; present address: 107 Awanti, OPP: Kamala Nehru Park, Erandawana, Pune, 411 004, India

P. Thiruchenthil Nathan

St. John's College, Palayamkottai, 627 002, India

D. Paramanantha Swami Doss

St. John's College, Palayamkottai, 627 002, India

See next page for additional authors

Follow this and additional works at: https://digitalcommons.unl.edu/bioscistorz

Part of the Genetics and Genomics Commons

Storz, Jay F.; Balasingh, J.; Bhat, Hari; Nathan, P. Thiruchenthil; Swami Doss, D. Paramanantha; Prakash, A. Antony; and Kunz, Thomas H., "Clinal variation in body size and sexual dimorphism in an Indian fruit bat, Cynopterus sphinx (Chiroptera: Pteropodidae)" (2001). Jay F. Storz Publications. 24.

https://digitalcommons.unl.edu/bioscistorz/24

This Article is brought to you for free and open access by the Papers in the Biological Sciences at DigitalCommons@University of Nebraska - Lincoln. It has been accepted for inclusion in Jay F. Storz Publications by an authorized administrator of DigitalCommons@University of Nebraska - Lincoln. 


\section{Authors}

Jay F. Storz, J. Balasingh, Hari Bhat, P. Thiruchenthil Nathan, D. Paramanantha Swami Doss, A. Antony Prakash, and Thomas H. Kunz 
Published in Biological Journal of the Linnean Society 72:1 (January 2001), pp. 17-31; doi 10.1111/j.1095-8312.2001.tb01298.x Copyright (C) 2001 The Linnean Society of London; published by Wiley-Blackwell Publishing. Used by permission.

http://www.wiley.com/bw/journal.asp?ref=0024-4066

Submitted January 20, 2000; accepted August 9, 2000.

\title{
Clinal variation in body size and sexual dimorphism in an Indian fruit bat, Cynopterus sphinx (Chiroptera: Pteropodidae)
}

\author{
Jay F. Storz, ${ }^{1}$ J. Balasingh, ${ }^{2}$ Hari R. Bhat, ${ }^{3}$ P. Thiruchenthil Nathan, ${ }^{2}$ \\ D. Paramanantha Swami Doss, ${ }^{2}$ A. Antony Prakash, ${ }^{2}$ Thomas H. Kunz ${ }^{1}$ \\ ${ }^{1}$ Department of Biology, Boston University, 5 Cummington Street, Boston, MA 02215, USA \\ ${ }^{2}$ Department of Zoology, St. John's College, Palayamkottai, 627 002, India \\ ${ }^{3}$ National Institute of Virology, Pune, 411 001, India; present address: 107 Awanti, OPP: Kamala Nehru Park, \\ Erandawana, Pune, 411 004, India
}

\begin{abstract}
Geographic variation in body size and sexual dimorphism of the short-nosed fruit bat (Cynopterus sphinx) was investigated in peninsular India. Bats were sampled at 12 localities along a 1,200 km latitudinal transect that paralleled the eastern flanks of the Western Ghats. The geographic pattern of variation in external morphology of C. sphinx conforms to the predictions of Bergmann's Rule, as indicated by a steep, monotonic cline of increasing body size from south to north. This study represents one of the first conclusively documented examples of Bergmann's Rule in a tropical mammal and confirms that latitudinal clines in body size are not exclusively restricted to temperate zone homeotherms. Body size was indexed by a multivariate axis derived from principal components analysis of linear measurements that summarize body and wing dimensions. Additionally, length of forearm was used as a univariate index of structural size to examine geographic variation in a more inclusive sample of bats across the latitudinal transect. Multivariate and univariate size metrics were strongly and positively correlated with body mass, and exhibited highly concordant patterns of clinal variation. Stepwise multiple regression on climatological variables revealed that increasing size of male and female C. sphinx was associated with decreasing minimum temperature, increasing relative humidity, and increasing seasonality. Although patterns of geographic size variation were highly concordant between the sexes, C. sphinx also exhibited a latitudinal cline in the magnitude and direction of sexual size dimorphism. The size differential reversed direction across the latitudinal gradient, as males averaged larger in the north, and females averaged larger in the south. The degree of female-biased size dimorphism across the transect was negatively correlated with body size of both sexes. Canonical discriminant analysis revealed that male- and female-biased size dimorphism were based on contrasting sets of external characters. Available data on geographic variation in the degree of polygyny in C. sphinx suggests that sexual selection on male size may play a role in determining the geographic pattern of sexual size dimorphism.
\end{abstract}

Keywords: Bergmann's Rule, Chiroptera, India, geographic variation, morphological variation, Pteropodidae, sexual selection, Western Ghats

\section{Introduction}

Variation in animal body size has functional consequences for a diverse array of life history attributes, and is therefore subject to an equally diverse array of selection pressures (Clutton-Brock \& Harvey, 1983; Lindstedt \& Swain, 1988). The multifaceted nature of adaptive variation in body size suggests that consistent spatial correlations with particular ecological variables are generally not to be expected. Nonetheless, geographic trends in size variation of many homeothermic species are well-characterized by empirical generalizations such as Bergmann's (1947) Rule. Mayr (1963: 320) interpreted Bergmann's Rule exclusively within the context of intraspecific variation: “... body size in geographically variable species averages larger in the 
cooler parts of the range of a species." The original physiological explanation for this pattern was that surface/volume ratio decreases as body size increases, so larger size reduces the rate of heat loss per unit body mass. Although the mass-specific rate of metabolism is inversely related to body mass, the total rate of metabolism (and hence, resource requirements) increases as a positive function of mass (McNab, 1971, 1999). Thus, the classical thermoregulatory explanation for Bergmann's Rule is valid only if the total rate of energy intake more than offsets the increased metabolic demands of large body size.

Empirical assessments of Bergmann's Rule primarily have been based on geographic surveys of temperate zone species at latitudes $>20^{\circ}$ (Zink \& Remsen, 1986; Zeveloff \& Boyce, 1988). However, altitudinal and latitudinal clines in body size have also been documented in many non-migratory tropical birds (Mayr, 1944; Mayr \& Vaurie, 1948; Ripley, 1950; Traylor, 1950; Moreau, 1957; Handford, 1983; Graves, 1991; Slowtow \& Goodfriend, 1996), suggesting that the adaptive basis of size variation may often involve factors other than (or in addition to) cold-tolerance.

In hot aridlands and tropical environments, geographic variation in the size of small-bodied homeotherms may often reflect an adaptive response to the challenges of conserving metabolic water and/or maximizing heat dissipation (Hamilton, 1958, 1961; Brown \& Lee, 1969 Power, 1969; James, 1970). Because the evaporative surface area/volume ratio is inversely proportional to body size, this hypothesis predicts that larger size is advantageous in hot arid environments, and smaller size is advantageous in hot humid environments. Intraspecific variation in birds of the genus Vireo provides supporting evidence, as birds are smallest in the humid lowland tropics of Central America, and largest in the hot, arid deserts of northern Mexico (Hamilton, 1958, 1961). Likewise, in the 12 species of North American birds studied by James (1970), body size (as indexed by wing length) was smallest in the hot, humid southeast and exhibited a progressive increase across a westward gradient of increasing aridity and a northward gradient of decreasing temperature.

Opinions vary with respect to the statistical validity of Bergmann's Rule in continental populations of birds (Wooler et al., 1985; Zink \& Remsen, 1987; Aldrich \& James, 1991) and mammals (McNab, 1971; Yom-Tov \& Nix, 1986; Zeveloff \& Boyce, 1988; Dayan et al., 1991). Rodents have been especially well-studied and often exhibit a considerable degree of clinal variation in body size (Brown \& Lee, 1969; Straney \& Patton, 1980; Owen, 1989; Baumgardener \& Kennedy, 1993; Smith et al., 1995). However, the direction of change across climatic gradients is not always consistent with the classical in- terpretation of Bergmann's Rule (McNab, 1971; Sullivan \& Best, 1997; Weigl et al., 1998). The adaptive basis of clinal variation in mammalian body size has most often been explained by invoking selection for thermoregulatory capabilities (Brown \& Lee, 1969) or selection for fasting endurance in climatically severe environments (Boyce, 1979; Searcy, 1980; Lindstedt \& Boyce, 1985; Millar \& Hickling, 1990). Alternatively, clinal variation in body size may reflect an ecophenotypic response to geographic variation in the nutritional resource base (e.g., Patton \& Brylski, 1987). In bats, empirical support for the validity for Bergmann's Rule is marginal (reviewed by Bogdanowicz, 1990). Even among tropical species that maintain thermal homeostasis, bats may be expected to depart from the pattern typical of homeotherms on the basis of both biophysical and ecological considerations. The highly vascularized, naked wingmembranes of bats increase the surface area/volume ratio relative to birds and non-volant mammals of similar body mass. Thus, geographic variation in overall body and wing dimensions may have important consequences for susceptibility to desiccation in hot, arid environments, and the capacity for heat dissipation in hot, humid environments.

Because body size is such a critical determinant of reproductive rates (Clutton-Brock \& Harvey, 1983), size variation may often have highly divergent consequences for males and females. Within the constraints imposed by genetic correlation between the sexes (Lande, 1980), the direction and magnitude of sexual dimorphism expressed in a given population may often reflect the interplay between fecundity selection on females and sexual selection on males (Ralls, 1977; Price, 1984). In bats, both male-biased and female-biased size dimorphism have been documented (Myers, 1978; Williams \& Findley, 1979; Findley \& Wilson, 1982; Ruedas et al., 1994; Willig \& Hollander, 1995), although the underlying causes of sex-limited selection pressures have not been demonstrated for any species. Myers (1978) suggested that female-biased size dimorphism in vespertilionid bats reflects an adaptive response to the aerodynamic challenges of flight during pregnancy (and lactation, if it involves aerial transport of suckling young). According to this hypothesis, larger size of females is an allometric effect of selection for reduced wing-loading. By contrast, Williams \& Findley (1979) argued that increased female size in vespertilionid bats reflects an adaptive response to the metabolic demands of maintaining thermal homeostasis during pregnancy. Both of these hypotheses are potentially applicable to a wider range of bat species beyond the Vespertilionidae. In addition to fecundity selection on females, sexual selection on males may also be an important driving force in the evolution of sexual dimorphism in bats. If body size influences suc- 
cess in territory acquisition and/or mating access to receptive females, the opportunity for sexual selection on male size is expected to be greatest in species characterized by highly polygynous mating systems (e.g., McCracken \& Bradbury, 1981; Storz et al., 2000b).

Here we report results of a field-based study of morphological variation in the short-nosed fruit bat, Cynopterus sphinx Vahl (Chiroptera: Pteropodidae). The primary objective of this study was to examine ecogeographic correlates of variation in overall body size within and between the sexes, and to test whether the observed patterns conform to Bergmann's Rule. Cynopterus sphinx has an extensive continental distribution across South Asia and is peripherally distributed along the western margin of the Malay Archipelago (Storz \&Kunz, 1999). This species exhibits an extensive degree of variation in body size, although the nature and geographic pattern of this variation has not been investigated previously. This analysis of size variation in Cynopterus sphinx permits an evaluation of the validity of Bergmann's Rule in a tropical mammal, and provides the opportunity to test predictions about patterns of clinal variation in body size across temperature and humidity gradients.

\section{Methods}

\section{Area of Study and Sampling Design}

The Western Ghats span a linear distance of approximately 1,600 km along the western coast of peninsular India, from the Tapti River $\left(21^{\circ} \mathrm{N}\right)$ to the southern tip of the subcontinent $\left(8^{\circ} \mathrm{N}\right)$. The crestline averages 900 $1,500 \mathrm{~m}$ in elevation and intercepts the southwest monsoon, thereby creating a rainshadow across the semiarid plains to the east. At lower elevations along the eastern flanks of the Ghats, tropical moist-deciduous and dry-deciduous forest typically grade into tropical thorn-scrub vegetation at the mountain/plains interface (Mani, 1974b; Subramanyam \& Nayar, 1974). Peninsular India is characterized by a smooth north-to-south gradient of increasing daily minimum temperature and increasing humidity (Mani, 1974a; Ramdas, 1974). The annual range of ambient temperature also varies with latitude, decreasing from the more seasonal Deccan Plateau to the more equable temperature regime of the Tamilnad Plains.

Bats were sampled along a latitudinal transect that spanned a distance of approximately $1,200 \mathrm{~km}$ along the eastern flanks of the Western Ghats, from $18^{\circ} 32^{\prime} \mathrm{N}$, $73^{\circ} 51^{\prime} \mathrm{E}$ (Pune) to $8^{\circ} 11^{\prime} \mathrm{N}, 7^{\circ} 30^{\prime} \mathrm{E}$ (Nagercoil; Figure 1). Bats were sampled at a total of 12 localities along this transect at elevations ranging from 30 to $900 \mathrm{~m}$, in habitats ranging from semi-arid tropical thorn forest to tropical deciduous forest at the mountain/plains interface.

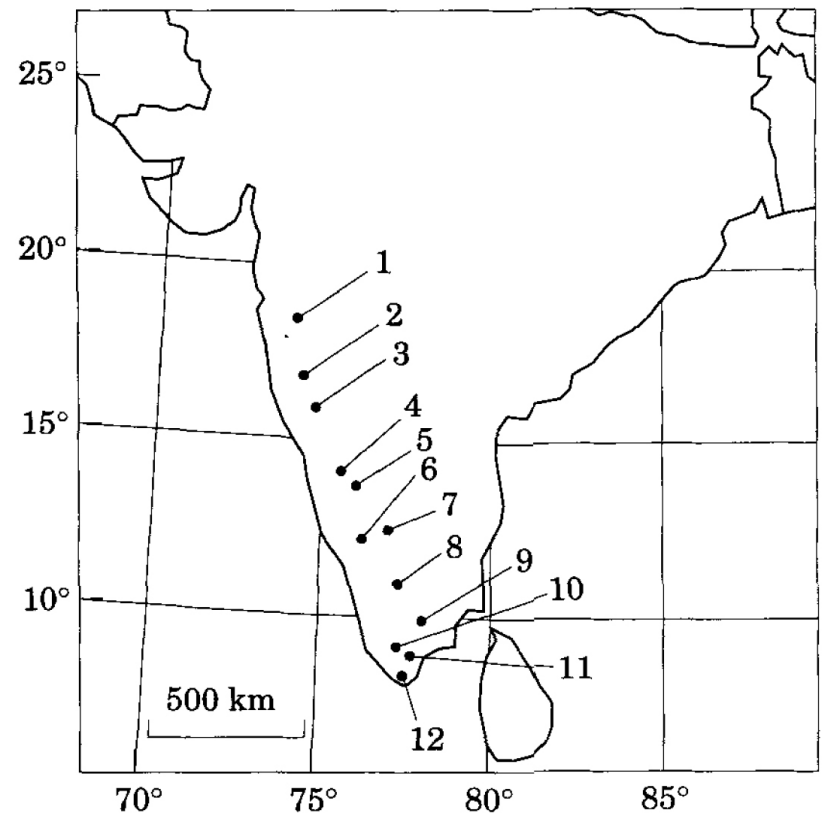

Figure 1. Map of peninsular India showing localities where Cynopterus sphinx was sampled. Names of sampling localities, geographic coordinates, and elevation (recorded to the nearest $10 \mathrm{~m}$ ) are as follows:
1. Pune
$18^{\circ} 32^{\prime} \mathrm{N}, 73^{\circ} 51^{\prime} \mathrm{E}, 600 \mathrm{~m}$
2. Kolhapur $16^{\circ} 42^{\prime} \mathrm{N}, 74^{\circ} 13^{\prime} \mathrm{E}, 560 \mathrm{~m}$
3. Belgaum
4. Sorab
5. Shimoga $15^{\circ} 54^{\prime} \mathrm{N}, 74^{\circ} 36^{\prime} \mathrm{E}, 900 \mathrm{~m}$ $14^{\circ} 05^{\prime} \mathrm{N}, 75^{\circ} 24^{\prime} \mathrm{E}, 620 \mathrm{~m}$ $13^{\circ} 56^{\prime} \mathrm{N}, 75^{\circ} 35^{\prime} \mathrm{E}, 650 \mathrm{~m}$
6. Thithimathi
7. Mysore
8. Metupalayam
9. Othakadai
10. Kuttalam
11. Palayamkottai
12. Nagercoil $12^{\circ} 05^{\prime} \mathrm{N}, 76^{\circ} 00^{\prime} \mathrm{E}, 860 \mathrm{~m}$ $12^{\circ} 18^{\prime} \mathrm{N}, 76^{\circ} 37^{\prime} \mathrm{E}, 780 \mathrm{~m}$ $11^{\circ} 18^{\prime} \mathrm{N}, 76^{\circ} 59^{\prime} \mathrm{E}, 450 \mathrm{~m}$ $9^{\circ} 56^{\prime} \mathrm{N}, 78^{\circ} 07^{\prime} \mathrm{E}, 150 \mathrm{~m}$ $8^{\circ} 58^{\prime} \mathrm{N}, 77^{\circ} 18^{\prime} \mathrm{E}, 170 \mathrm{~m}$ $8^{\circ} 44^{\prime} \mathrm{N}, 77^{\circ} 42^{\prime} \mathrm{E}, \quad 50 \mathrm{~m}$ $8^{\circ} 11^{\prime} \mathrm{N}, 77^{\circ} 30^{\prime} \mathrm{E}, \quad 30 \mathrm{~m}$

Sampling localities were located in the states of Maharashtra (1-2), Karnataka (3-7), and Tamil Nadu (8-12).

The transect spanned the Nilgiri Hills, a transverse range that forms the point of convergence between the Western and Eastern Ghats and demarcates the Deccan Plateau from the uplands and coastal plains of Tamil Nadu to the South.

Bats were trapped on foraging grounds using $2 \mathrm{~m}$ $\times 6 \mathrm{~m}$ nylon mistnets that were deployed in areas with fruit-bearing trees. In Pune and Palayamkottai, bats were also trapped in diurnal foliage-roosts as described in Storz et al. (2000a,b). Each individual was classified as juvenile or adult based on the degree of fusion of the metacarpal-phalangeal epiphyses (Anthony, 1988). Only adults were used in the subsequent analysis of morphological variation. With the exception of those retained as voucher specimens, bats were released at the site of capture after processing. 


\section{Analysis of Morphometric Variation}

Morphometric variation was assessed in C. sphinx by examining eight external characters defined in Kitchener \& Maharadatunkamsi (1991) that jointly summarize overall body dimensions and wing area: length of tibia, length of forearm, length of metacarpal of digits 25 (DIG2-DIG5), proximal phalanx of digit 3 (DIG3P1), and body mass. External characters were measured to the nearest $0.1 \mathrm{~mm}$ using dial calipers and body mass was measured using a $100 \mathrm{~g}$ spring balance. All measurements were taken by JFS. All variables were $\log _{10^{-}}$ transformed and screened for normality, equality of variances, and equality of variance-covariance matrices. Body mass was considered separately from other external characters. Morphological variation within and between the sexes was initially examined by means of multivariate analysis of variance (MANOVA) and univariate ANOVA with two-way factorial design. Sex and geographic locality were included as fixed-effect factors (model I ANOVA). The factorial design provided tests of three null hypotheses: (1) no effect of geographic locality, (2) no sexual dimorphism, and (3) no geographic variation in sexual dimorphism (as indicated by locality $\times$ sex interaction).

In studies of geographic variation, a variety of different multivariate and univariate approaches have been used to measure animal body size. In morphological studies of vertebrates, overall body size is typically indexed by a multivariate axis derived from external, osteometric, and/or craniometric characters (Mosimann \& James, 1979; Grant et al., 1985; Rising \& Somers, 1989; Freeman \& Jackson, 1990; Patton \& Smith, 1992). In bats, a multivariate axis that summarizes body and wing dimensions should provide a functionally relevant measure of structural size for the purpose of testing predictions related to Bergmann's Rule. Accordingly, principal components analysis was performed on the variance-covariance matrix of $\log _{10}$-transformed variables to extract an allometric size vector. The analysis was conducted separately for each sex. Variation in the first principal component (PC1) was analyzed for a subset of the total sample of bats. Length of forearm was used as a univariate index of structural size to examine geographic variation in the full sample of bats across the transect. If PC1 and length of forearm do, in fact, provide accurate and functionally meaningful representations of overall structural size, both metrics should covary with body mass in a positive, linear fashion (Rising \& Somers, 1989). This relationship was tested by means of bivariate correlation analysis. Body mass combines information about overall structural size in addition to a more variable component that reflects nutrient-reserve storage (Piersma \& Davidson, 1991). Thus, in order to control for seasonal and in- terannual variation in reproductive condition and nutrient stores, the analysis of body mass was restricted to males and nonpregnant females sampled during a single 8 week period following the dry-season parturition period (March 4 through May 2, 1998).

Variation among localities in PC1 and length of forearm was examined using single-classification ANOVA. The geographic pattern of size variation among particular localities was investigated using Hochberg's GT2method for multiple comparisons (Sokal \& Rohlf, 1995: 247-252). The results of correlation analyses are presented as Pearson's product-moment correlation coefficients. Stepwise multiple regression analysis was used to examine the relationship between body size of males and females (as indexed by PC1) and the following climatological variables: mean annual temperature, mean maximum daily temperature, mean minimum daily temperature, annual range in temperature, mean annual rainfall, mean maximum rainfall during the wettest month, mean minimum rainfall during the driest month, and annual range in total rainfall. Climatological data were obtained from meteorological stations located within $30 \mathrm{~km}$ of each sampling locality. Weighted mean values of ecogeographic variables for each locality were used for pooled samples. To control for multicolinearity, temperature and precipitation variables were reduced to a smaller set of orthogonal vectors by means of principal components analysis on the correlation matrix. Climatic principal components were used as independent variables in the multiple regression analysis.

Both multivariate and univariate tests of sexual dimorphism were conducted on samples from each general locality. The degree of sexual dimorphism in body size was quantified as the difference between females and males in PC1 factor scores, obtained by conducting the principal components analysis on the pooled sample of both sexes. Canonical discriminant analysis was used to determine the relative contributions of each linear combination of morphometric variables to the observed pattern of multivariate differentiation between the sexes. Factor loadings on the first canonical variate axis provided a measure of the relative discriminatory power of individual characters. However, high communalities among variables can produce factor loadings that belie the true discriminatory power of individual characters that differ between the sexes. Following Willig \& Hollander (1995), the relative importance of each character in discriminating between the sexes was ascertained by the magnitude of correlation between the original variable and individual scores on the canonical variate axis. The square of the correlation coefficient (importance value) measures the fraction of the variation in discriminant-function scores accounted for by variation in the original morphometric character. The consis- 
Table 1. Statistics describing length of forearm of adult Cynopterus sphinx sampled from peninsular India. Statistics are reported for general localities used in the univariate ANOVA. The southern Tamil Nadu group comprises samples from Kuttalam, Palayamkottai, and Nagercoil.

\begin{tabular}{|c|c|c|c|c|c|c|c|c|}
\hline Locality & \multicolumn{4}{|l|}{ Males } & \multicolumn{4}{|l|}{ Females } \\
\hline Kolhapur/Belgaum & $71.7 \pm 1.9$ & $67.2-74.5$ & 3.52 & 16 & $71.6 \pm 2.2$ & $66.3-75.7$ & 4.62 & 48 \\
\hline Sorab/Shimoga & $69.6 \pm 2.5$ & $65.8-74.4$ & 6.38 & 21 & $69.6 \pm 1.8$ & $66.8-73.5$ & 3.19 & 9 \\
\hline Metupalayam & $68.4 \pm 2.5$ & $64.4-72.8$ & 6.46 & 11 & $69.2 \pm 2.2$ & $63.0-72.5$ & 4.82 & 19 \\
\hline Othakadai & $68.2 \pm 1.8$ & $65.0-72.1$ & 3.25 & 20 & $69.7 \pm 1.7$ & $67.1-72.4$ & 2.95 & 11 \\
\hline Southern Tamil Nadu & $67.5 \pm 2.1$ & $61.8-74.4$ & 4.40 & 122 & $68.0 \pm 2.1$ & $60.2-73.9$ & 4.52 & 154 \\
\hline Total & $69.3 \pm 3.2$ & $61.8-79.3$ & 10.42 & 241 & $71.4 \pm 3.3$ & $60.2-80.1$ & 10.89 & 516 \\
\hline
\end{tabular}

tency with which a particular set of characters contributes to the expression of secondary sexual dimorphism can then be examined by comparing profiles of traitspecific importance values among different populations. A highly positive correlation between profiles of importance values in different populations is interpreted as evidence for geographical uniformity in the morphological basis of sexual dimorphism. The analyses were conducted separately on latitudinal subdivisions of transect point samples.

\section{Results}

A total of 757 adult C. sphinx were sampled along the transect. The multivariate analysis of external morphology was based on a subset of 256 bats while length of forearm was analyzed for the full sample. In all analyses, samples of C. sphinx from Sorab and Shimoga were pooled. Additionally, when males and females were considered separately in multivariate and univariate analyses, adjacent point samples were pooled as follows: Kolhapur/Belgaum, Thithimathi/Mysore, and the three southernmost localities (Kuttalam/Palayamkottai/Nagercoil). These pooled samples compensated for unbalanced representation of the sexes at individual localities. Variance component analysis confirmed that each grouping of adjacent localities constituted a statistically homogeneous subset of transect point samples.

The multivariate analysis was based on $\log _{10}$-transformed values of all external characters except body mass. Univariate normality and equality of error variances was confirmed for each variable. No inequality of variance-covariance matrices was detected in samples of C. $\operatorname{sphinx}$ (Box's test: $M=414.627 ; F=1.089 ; \mathrm{d} f=308$, 15444; $P=0.139$ ). With regard to $\log _{10}$-length of forearm for the full sample of bats, no statistically significant de- partures from normality were detected (one-sample Kolmogorov-Smirnov test: $Z=1.305 ; n=757 ; P=0.066$ ) and no inequality of variances among point samples was evident (Levene's test: $F=0.675 ; \mathrm{d} f=11,745 ; P=0.763$ ). Length of forearm of males ranged from $61.8 \mathrm{~mm}$ to 79.3 $\mathrm{mm}$, a difference of $28 \%$. In females, length of forearm ranged from $60.2 \mathrm{~mm}$ to $80.1 \mathrm{~mm}$, a difference of $33 \%$ (Table 1). Variation in body mass for the 1998 subset of males and nonpregnant females also conformed to a lognormal distribution (one-sample Kolmogorov-Smirnov test: $Z=0.994 ; n=329 ; P=0.277$ ) and exhibited a relatively greater range of variation: $75 \%$ in males (38.7 g$67.9 \mathrm{~g}$ ) and $78 \%$ in non-pregnant females (39.0 g-69.5 g).

The two-way MANOVA revealed a highly significant effect of locality, a marginally significant effect of sex, and a highly significant locality $\times$ sex interaction (Table 2A). Univariate $F$-tests on each external character of $C$. sphinx revealed a uniformly high degree of heterogeneity among localities $(P<0.001$ for all variables). Singlevariable tests also revealed statistically significant differences between the sexes for DIG3, DIG4, and DIG5 $(P<$ $0.05)$ and a significant locality $\times$ sex interaction for DIG4 $(P<0.05)$. The geographic pattern of multivariate differences between the sexes is evaluated in more detail below. Univariate analyses of length of forearm also revealed a high degree of heterogeneity among localities, but differences between the sexes were not statistically significant (Table 2B). Males and females were treated separately in subsequent analyses.

\section{Geographic Variation in Body Size}

In both sexes of C. sphinx, the first axis of the principal components analysis (E1) was clearly interpretable as an overall size vector. Factor loadings for all characters 
Table 2. Effects of geographic locality and sex on variation in external morphology of Cynopterus sphinx as revealed by MANOVA and univariate ANOVA with two-way factorial design. The multivariate analysis is based on seven external characters for a subset of bats $(n=256)$. The univariate analysis is based on length of forearm for the full sample of bats $(n=757)$.

\begin{tabular}{lllcrr}
\hline (a) Multivariate analysis & Effect & $\mathrm{d} f$ & Pillai's trace & $F$ & $P$ \\
\hline & Locality & 35,1210 & 0.958 & 8.190 & $<0.001$ \\
& Sex & 7,238 & 0.056 & 2.021 & 0.053 \\
& Locality $\times$ sex & 35,1210 & 0.266 & 1.946 & 0.001 \\
\hline (b) Univariate analysis & Effect & $\mathrm{d} f$ & Type III SS & $F$ & $P$ \\
\hline & Locality & 10 & 0.138 & 84.506 & $<0.001$ \\
& Sex & 1 & $3.893 \times 10^{-4}$ & 2.376 & 0.124 \\
& Locality $\times$ sex & 10 & $2.467 \times 10^{-3}$ & 1.506 & 0.133 \\
& Error & 735 & 0.120 & & \\
\hline
\end{tabular}

Table 3. Factor loadings of seven external variables on the first principal component axis (PC1) computed for males and females of Cynopterus sphinx. Principal components analysis was conducted on each sex separately, and PC1 was extracted from the variance-covariance matrix of $\log _{10}$-transformed variables. See text for abbreviations of characters.

\begin{tabular}{lcc}
\hline Variable & $\begin{array}{c}\text { Males } \\
(n=100) \\
\text { PC1 }\end{array}$ & $\begin{array}{c}\text { Females } \\
(n=156) \\
\text { PC1 }\end{array}$ \\
\hline Length of forearm & 0.920 & 0.903 \\
Length of tibia & 0.907 & 0.883 \\
Length of DIG2 & 0.954 & 0.929 \\
Length of DIG3 & 0.969 & 0.938 \\
Length of DIG3P1 & 0.865 & 0.914 \\
Length of DIG4 & 0.961 & 0.921 \\
Length of DIG5 & 0.948 & 0.834 \\
Variance explained (\%) & 87.0 & 81.7 \\
Eigenvalue & 6.09 & 5.72 \\
\hline
\end{tabular}

were uniformly high and positive (Table 3). Moreover, PC1 was strongly and positively correlated with body mass in males $(r=0.820, n=100, P<0.001)$ and nonpregnant females $(r=0.741, n=137, P<0.001)$, as illustrated in Figure 2. Single-classification ANOVA revealed a high degree of heterogeneity in mean PC1 among localities for both males $(F=21.963, \mathrm{~d} f=5$, 94, $P<0.001)$ and females $(F=27.067, \mathrm{~d} f=5,150, P<0.001)$. Mean PC1 scores for both sexes exhibited a progressive increase from south to north, indicating a latitudinal cline in overall body size (Figure 3).Multiple comparisons using Hochberg's GT2-method revealed similar geographic patterns of size variation in both sexes. The interval between Sorab/Shimoga and Kolhapur/Bel- gaum represented a statistically significant demarcation between southern and northern subdivisions of the transect $(P<0.05)$. In females, samples from Kolhapur/Delgaum and Pune were also identified as statistically distinct subsets.

The pattern of clinal variation in body size was further substantiated by analysis of length of forearm for the full sample of bats across the transect. Length of forearm exhibited high factor loadings on PC1 (Table 3) and a low coefficient of variation relative to other external characters, and therefore provided a useful univariate index of overall body size. Length of forearm also was strongly and positively correlated with body mass in males $(r=0.814, P<0.01, n=100)$ and nonpregnant females $(r=0.731, P<0.01, n=229)$, as illustrated in Figure 4 . The magnitude of correlations remained similar even when considering the full sample of bats collected in different seasons and different years (males: $r$ $=0.708, P<0.001, n=241$, and non-pregnant females: $r=0.741, P<0.001, n=401)$. In accordance with the multivariate analysis, single-classification ANOVA revealed a significant degree of heterogeneity among localities in mean length of forearm for males $(F=51.005$, $\mathrm{d} f=6,234, P<0.001)$ and females $(F=136.532, \mathrm{~d} f=$ $6,509, P<0.001)$. Differentiation among localities in length of forearm was chiefly attributable to a monotonic cline in body size (Figure 5). Mean length of forearm at Pune $(73.9 \mathrm{~mm})$, the northernmost locality on the transect, was 9.8\% larger than at Nagercoil (67.3 $\mathrm{mm}$ ), the southernmost locality. Multiple comparisons revealed that Pune exhibited the greatest degree of differentiation in samples of both sexes. The remaining localities were grouped into three statistically homogeneous subsets, all of which were partially overlapping. As illustrated in Figure 6, body mass exhibited a highly concordant pattern of clinal variation relative to PC1 and length of forearm. 

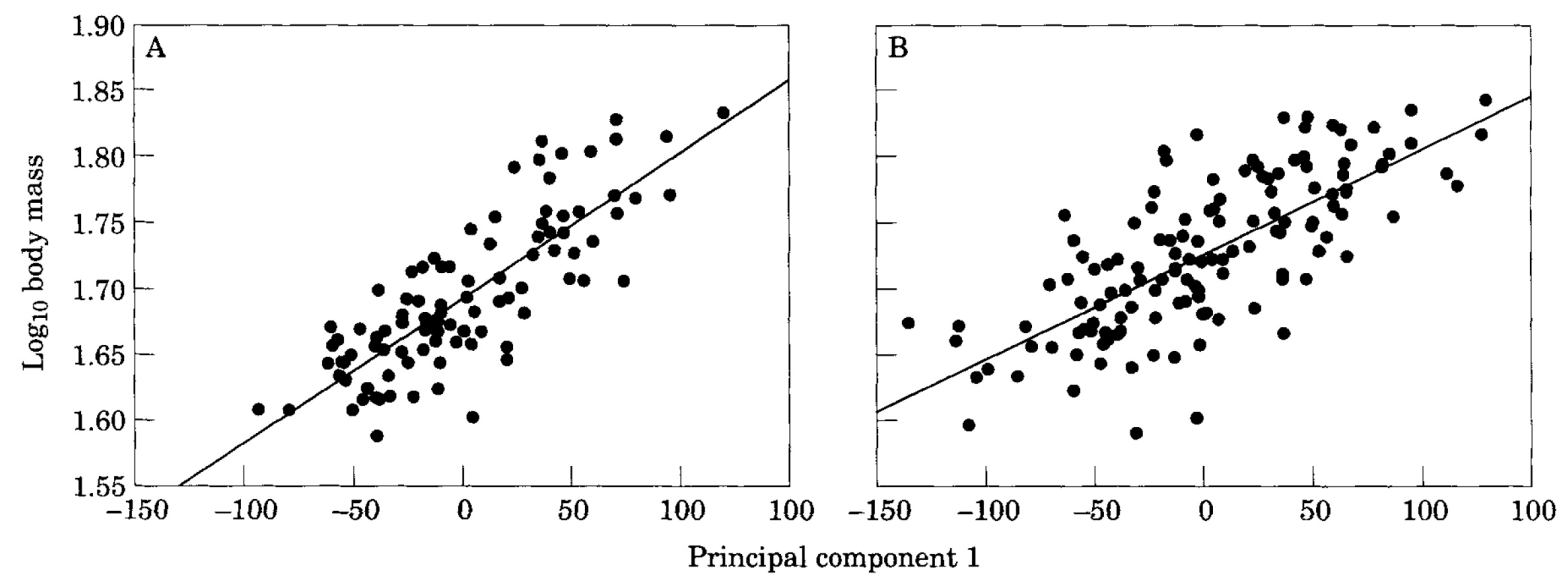

Figure 2. Bivariate plots of $\log _{10}$-body mass vs. PC1 for $(\mathrm{A})$ males $(n=100)$ and (B) nonpregnant females $(n=156)$ of $C y n o p t e r u s$ sphinx. All bats were sampled during an 8-week period in the 1998 dry season. Least squares linear regression lines are shown for illustration.

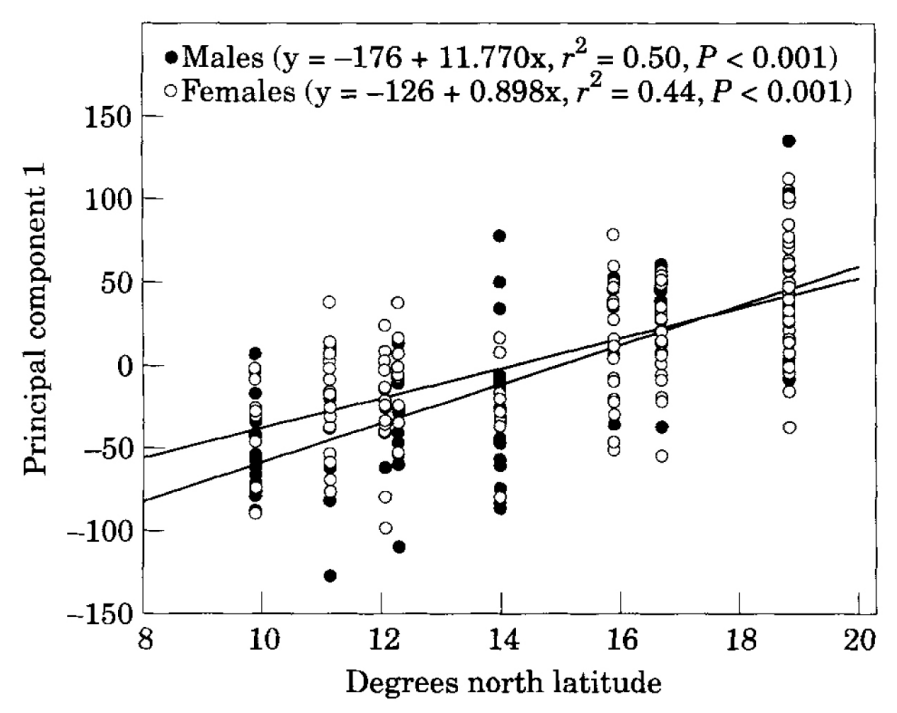

Figure 3. Model I linear regression of PC1 against latitude for males $(n=100)$ and females $(n=156)$ of Cynopterus sphinx sampled in peninsular India.

\section{Influence of Ecogeographic Factors on Body Size}

The first axis of the principal components analysis on temperature variables (PC1-T) explained $79.2 \%$ of the variance among localities (eigenvalue $=3.96$ ). Correlations between the original variables and PC1-T factor scores were high and positive (maximum temperature, $r=0.523$; minimum temperature, $r=0.985$; average temperature, $r=0.741$; wet-bulb temperature, $r=0.943$ ), except for annual range of temperature (an index of seasonality), which exhibited a strong negative correlation $(r=-0.677)$. PC1-T was interpreted as an overall temperature/equability vector. The first axis of the principal components analysis on rainfall variables (PC1-R) explained $73.1 \%$ of the variance among localities (eigen- value $=2.92)$. Correlations between original variables and PC1-R factor scores were uniformly high and positive (maximum rainfall, $r=0.986$; minimum rainfall, $r$ $=0.942$; average rainfall, $r=0.971$; annual range of rainfall, $r=0.848)$. PC1-R was therefore clearly interpretable as an overall rainfall vector. The second axis of the principal components analysis on rainfall variables (PC2-R) explained $26.0 \%$ of the variance among localities (eigenvalue $=1.04)$. This vector contrasted minimum rainfall $(r$ $=-0.277)$ and average rainfall $(r=-0.167)$, against maximum rainfall $(r=0.212)$ and annual range of rainfall $(r=$ 0.573). PC2-R was interpreted as a measure of seasonality of rainfall. Principal components analysis of temperature and rainfall variables thus produced an ordination of sampling localities across a north-to-south gradient of increasing minimum, maximum, and mean temperature, increasing relative humidity (as indexed by wetbulb temperature), and decreasing seasonality of temperature and precipitation.

Associations between PC1 and ecogeographic variables were highly concordant between the sexes (Table 4). The inverse correlation between latitude and longitude reflects the northwest to southeast orientation of the transect. Similarly, elevation along the transect increases as a positive function of latitude. Partial correlation analysis revealed that when latitude was held constant, longitude and elevation were not significantly associated with PC1 scores of males (longitude, $r=-0.227, P=0.824$; elevation, $r=-0.141, P=0.165$ ) or females (longitude, $r$ $=0.071, P=0.381$; elevation, $r=-0.064, P=0.426)$. With regard to climatological variables, PC1 scores of males and females were most strongly correlated with the temperature vector (PC1-T)and the second rainfall vector (PC2-R). These same variables emerged as the best predictors of size variation in the stepwise multiple regression analysis (Table 5). The magnitude and sign of 


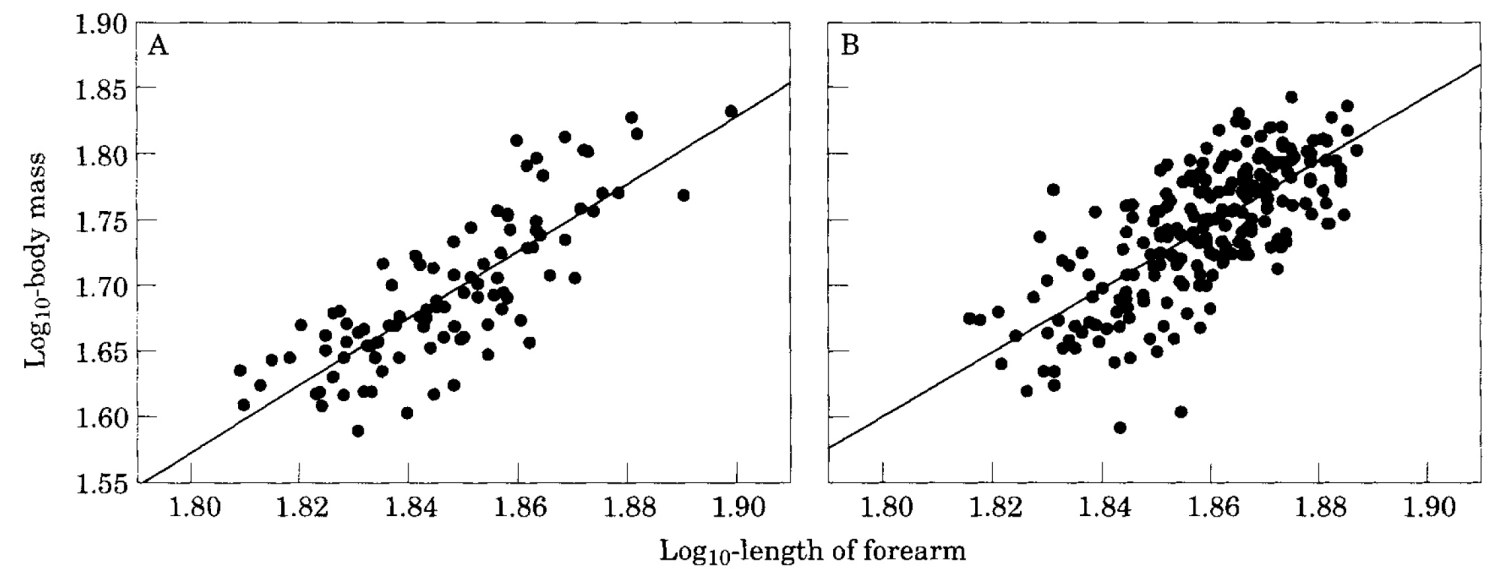

Figure 4. Bivariate plots of $\log _{10}$-body mass vs. $\log _{10}$-length of forearm for $(\mathrm{A})$ males $(n=100)$ and $(\mathrm{B})$ nonpregnant females $(n=$ 229) of Cynopterus sphinx. All bats were sampled during an 8 week period in the 1998 dry season. Least squares linear regression lines are shown for illustration.

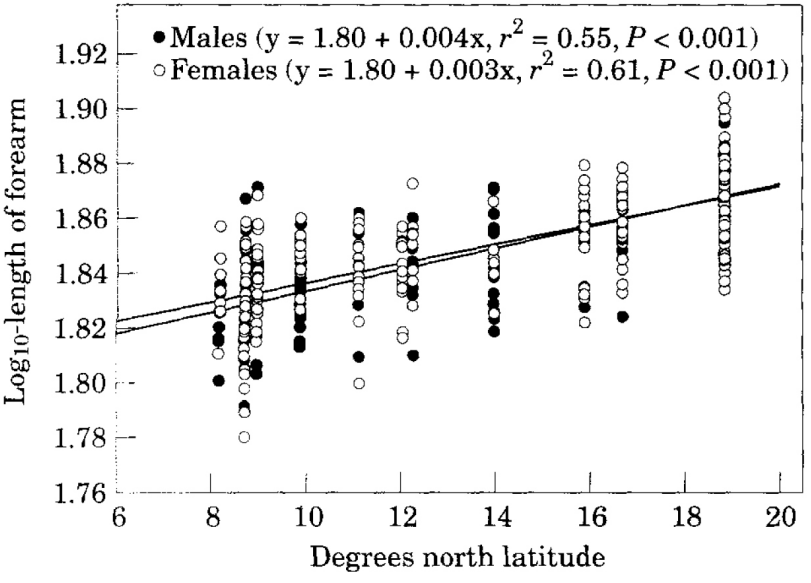

Figure 5. Model I linear regression of $\log _{10}$-length of forearm against latitude for males $(n=100)$ and females $(n=156)$ of Cynopterus sphinx sampled in peninsular India.

the standardized regression coefficients indicated that increasing body size of both sexes was primarily associated with decreasing minimum temperature, decreasing relative humidity, and increasing seasonality.

\section{Geographic Variation in Sexual Dimorphism}

A statistically significant degree of sexual dimorphism in overall body dimensions of C. sphinx was detected in the northernmost locality (Pune), and in two of the southern localities (Table 6). The size differential reversed direction across the latitudinal gradient, as males averaged slightly larger in the north, and females averaged slightly larger in the south. The degree of femalebiased size dimorphism across the transect was negatively correlated with body size (PC1) of both males $(r$ $=-0.911, P=0.011)$ and females $(r=-0.830, P=0.041)$.

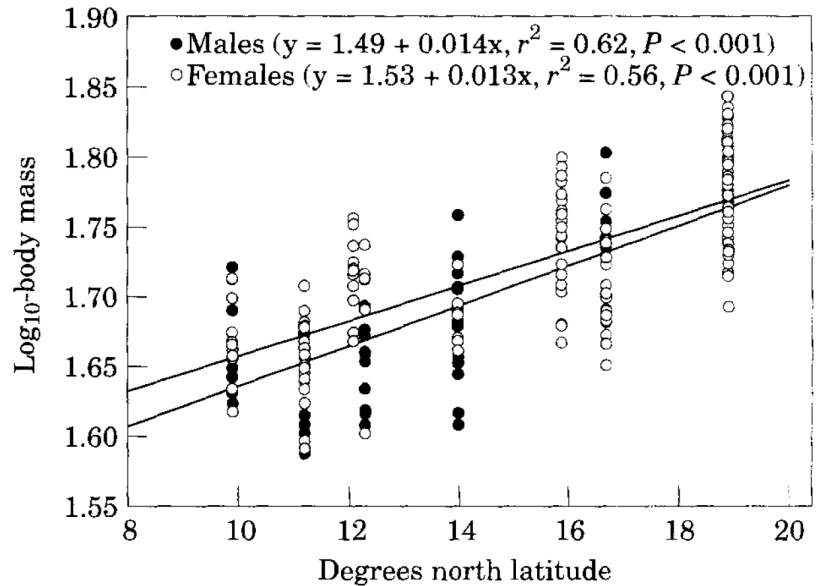

Figure 6. Model I linear regression of $\log _{10}$-body mass against latitude for males $(n=100)$ and females $(n=229)$ of Cynopterus sphinx sampled in peninsular India during an 8 week period in the 1998 dry season.

Variation between the sexes in length of forearm mirrored the latitudinal pattern revealed by the multivariate analysis; males averaged larger in the northernmost localities, and females averaged larger in all localities $<15^{\circ} \mathrm{N}$. The female- biased size differential in length of forearm was statistically significant in Othakadai $(F$ $=5.302 ; \mathrm{d} f=1,29 ; P=0.029)$ and approached statistical significance in the southern Tamil Nadu localities $(F=$ 3.419; $\mathrm{d} f=1,274 ; P=0.066$ ). The degree of female-biased size dimorphism in length of forearm across the transect was negatively correlated with mean values for males $(r$ $=-0.616, P=0.140)$ and females $(r=-0.777, P=0.040)$.

Having revealed a significant locality $\times$ sex interaction by means of two-way MANOVA (Table 2A), a canonical discriminant analysis was used to investigate the geographic pattern of sexual dimorphism in C. sphinx in more detail. Point samples on the transect were pooled 
Table 4. Pearson product-moment correlations among body size of male and female Cynopterus sphinx (as indexed by PC1), geographic variables, and principal components of variation in temperature (PC1-T), and rainfall (PC1-R and PC2-R).

\begin{tabular}{|c|c|c|c|c|c|c|c|c|}
\hline & PC1 males & PC1 females & Latitude & Longitude & Elevation & PC1-T & PC1-R & PC2-R \\
\hline PC1 males & 1.00 & $0.986^{* *}$ & $0.691^{* *}$ & $-0.642^{* *}$ & $0.414^{* *}$ & $-0.450^{* *}$ & 0.134 & $0.327^{* *}$ \\
\hline Latitude & & & 1.00 & $-0.934^{* *}$ & $0.520^{* *}$ & $-0.780^{* *}$ & $0.190^{*}$ & $0.502^{* *}$ \\
\hline Longitude & & & & 1.00 & $-0.582^{* *}$ & $0.773^{* *}$ & $-0.378^{* *}$ & $-0.444^{\text {** }}$ \\
\hline Elevation & & & & & 1.00 & $-0.892^{* *}$ & $0.317^{* *}$ & 0.039 \\
\hline PC1-R & & & & & & & 1.00 & 0.052 \\
\hline PC2-R & & & & & & & & 1.00 \\
\hline
\end{tabular}

* $P<0.05, * * P<0.01$

Table 5. Results of stepwise multiple regression analyses of body size of male and female Cynopterus sphinx (as indexed by PC1) against climatic variables. The following stepwise criteria were employed probability of $F$-to-enter $<0.050$, and probability of $F$-toremove $>0.100$. The standardized regression coefficients express the importance of particular independent variables in determining the value of PC1, when other variables are held constant. The coefficients of multiple determination $\left(R^{2}\right.$ and adjusted $\left.R^{2}\right)$ for all entered variables are given in parentheses below. These coefficients express the fraction of the total variability of PC1 attributable to the effects of the independent variables, as defined by the regression model fit to the data.

\begin{tabular}{lll}
\hline & PC1 (Males) & PC1 (Females) \\
\cline { 2 - 3 } Climatological variables & Standardized regression coefficient & Standardized regression coefficient \\
\hline PC1-Temperature & $-0.615(P<0.001)$ & $-0.462(P<0.001)$ \\
PC1-Rainfall & $0.018(P=0.817)$ & $-0.108(P=0.094)$ \\
PC2-Rainfall & $0.524(P<0.001)$ & $0.461(P<0.001)$ \\
& $\left(R^{2}=0.451\right.$, adjusted $\left.R^{2}=0.433\right)$ & $\left(R^{2}=0.421\right.$, adjusted $\left.R^{2}=0.410\right)$ \\
\hline
\end{tabular}

Table 6. Degree of sexual dimorphism of Cynopterus sphinx as revealed by two-sample MANOVA for six general localities. Direction of the size differential indicates which sex averages larger in size across all external characters.

\begin{tabular}{lccccc}
\hline Localities (North to South) & Direction & $\mathrm{d} f$ & Hotelling's $T^{e}$ & Exact $F$ & $P$ \\
\hline Pune & $\hat{0}>\uparrow$ & 7,53 & 0.242 & 2.417 & 0.032 \\
Kolhapur/Belgaum & $\hat{0}>+$ & 7,56 & 0.133 & 1.222 & 0.306 \\
Sorab/Shimoga & $\hat{0}<+$ & 7,22 & 0.233 & 0.953 & 0.488 \\
Thithimathi/Mysore & $\hat{0}<+$ & 7,32 & 0.386 & 2.879 & 0.019 \\
Metupalayam & $\hat{0}<q$ & 7,22 & 0.574 & 4.227 & 0.004 \\
Othakadai & $\hat{0}<+$ & 7,23 & 0.316 & 1.516 & 0.211 \\
\hline
\end{tabular}

into three latitudinal subdivisions: northern $\left(>15^{\circ} \mathrm{N}\right)$, central $\left(11-15^{\circ} \mathrm{N}\right)$, and southern $\left(<11^{\circ} \mathrm{N}\right)$. Each of the three analyses included $\geq 30$ individuals of each sex. The canonical discriminant analysis revealed statistically significant differences between the sexes in the southern subdivision (eigenvalue $=0.322$, Wilks' $\Lambda=0.756, \mathrm{~d} f=$ $7, P=0.030$ ), but not in the central (eigenvalue $=0.171$, Wilks' $\Lambda=0.854, \mathrm{~d} f=7, P=0.178$ ) or northern subdivisions (eigenvalue $=0.096$, Wilks' $\Lambda=0.912, \mathrm{~d} f=7, P=$ 0.140). Within each subdivision, the direction of the size differential was uniform across all characters (Figure 7). Males averaged larger in all external characters in the northern subdivision, and females averaged larger in all characters in the central and southern subdivisions. Profiles of importance values in the northern subdivision were negatively correlated with those of the central $(r=$ -0.228, $P=0.622)$ and southern subdivisions $(r=-0.572$, $P=0.179)$. This pattern indicated that male- and femalebiased size dimorphism were based on contrasting sets of external characters. Female-biased size dimorphism 

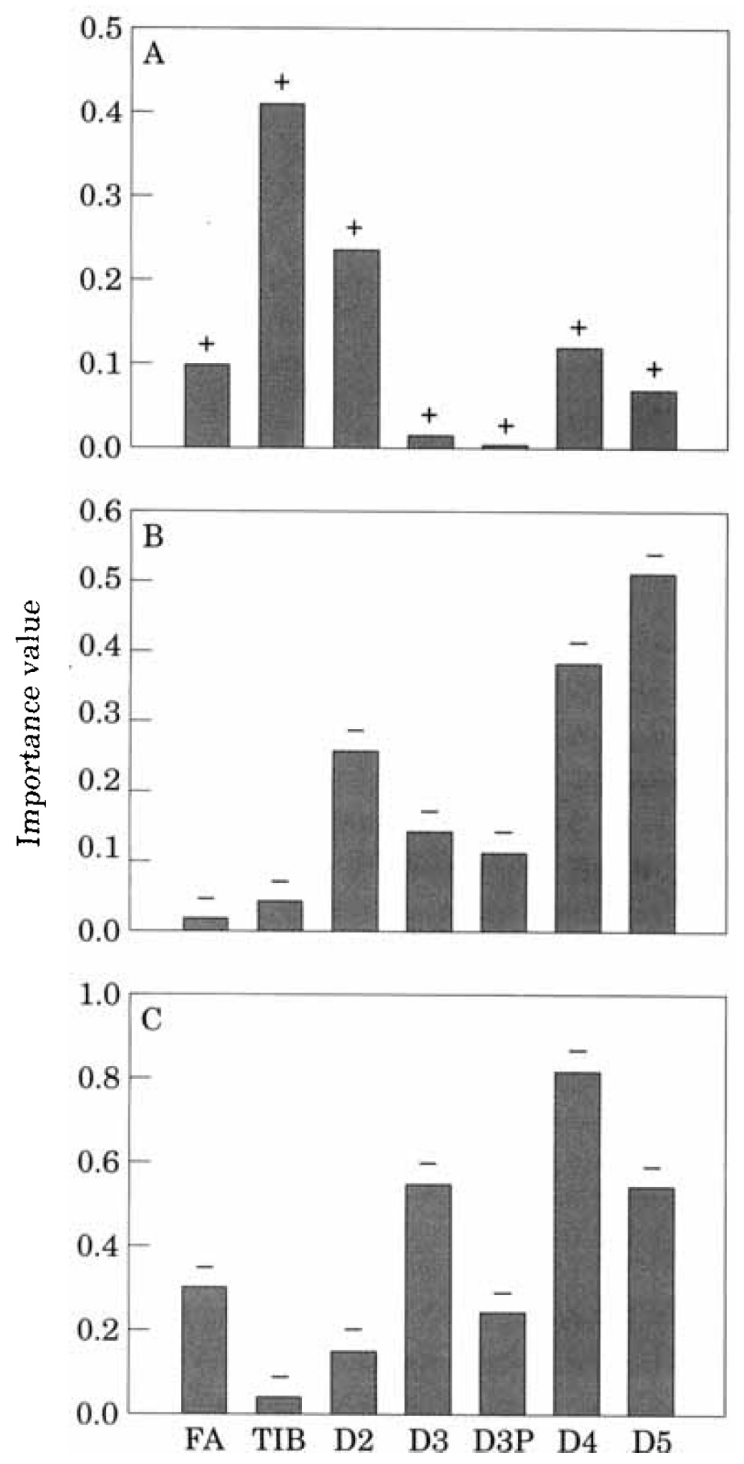

Figure 7. Profiles of importance values for seven external characters that distinguish between the sexes in Cynopterus sphinx. Point samples on the transect were pooled into three latitudinal subdivisions: A, northern $\left(>15^{\circ} \mathrm{N}\right)$; $\mathrm{B}$, central $\left(11-15^{\circ} \mathrm{N}\right)$; and $C$, southern $\left(<11^{\circ} \mathrm{N}\right)$. Importance values are estimates of the fraction of morphometric variance between the sexes attributable to a particular character. The sign above each bar indicates direction of the size differential for each character; a plus $(+)$ indicates that males are larger than females, and a minus $(-)$ indicates that females are larger than males. See text for abbreviations of characters.

was primarily attributable to a proportional increase in the area of the hand-wing, as indicated by the high importance values for DIG3, DIG4, and DIG5 in the southern subdivision. By contrast, male-biased dimorphism in the northern subdivision was primarily attributable to length of tibia and DIG2, although importance values were low for most characters. Although direction of the size differential was similar in the central and southern subdivisions, profiles of importance values were not strongly correlated $(r=0.630, P=0.129)$. Lack of statistical significance likely reflects the fact that the overall degree of sexual size dimorphism was relatively subtle.

\section{Discussion}

\section{Geographic Variation in Body Size}

The pattern of geographic variation in the external morphology of Cynopterus sphinx conforms to Bergmann's Rule, as indicated by a monotonic cline of increasing body size from south to north. Multivariate and univariate indices of structural size were strongly and positively correlated with body mass, and exhibited highly concordant patterns of clinal variation. This study represents one of the first conclusively documented examples of Bergmann's Rule in a tropical mammal and provides further confirmation that latitudinal clines in body size are not exclusively restricted to temperate zone homeotherms (Graves, 1991).

In pteropodid bats, basal metabolic rate is highly size-dependent and medium-sized frugivorous species such as C. sphinx are typically characterized by precise regulation of body temperature (McNab, 1989; $\mathrm{McNab}$ \& Bonaccorso, 1995). Because the energetics of temperature regulation have important consequences for fecundity, gestation period, and rates of postnatal growth in bats (McNab, 1982; Kunz, 1987), the ecologically optimal body size of non-migratory species may be expected to vary geographically in response to broad-scale climatic gradients. However, pteropodid bats are also known to employ a diverse array of physiological and behavioral strategies to maintain heat and water balance in extreme environments (McNab \& Bonaccorso, 1995; Ochoa-Acuña \& Kunz, 1999), so adaptive adjustments to environmental challenges may not necessarily entail changes in gross morphology. Although many pteropodid species occupy day-roosts in highly exposed situations such as tree canopies, roosting groups of $C$. sphinx typically aggregate in confined spaces such as tree hollows or modified foliage roosts (Bhat \& Kunz, 1995; Balasingh et al., 1995; Storz et al., 2000a,b). Cynopterus sphinx has a polyestrus reproductive cycle and adult females are either pregnant or lactating throughout most of the year (Storz \& Kunz, 1999). Aggregation into tightly clustered groups can significantly alter the microclimate of diurnal roosts, thereby minimizing energetic costs to reproductive females and mitigating the effects of adverse temperature and humidity conditions in the outside environment (Kunz, 1982). With regard to the thermoregulatory capacities of birds and mammals, Scholander (1955) argued that such behavioral adjust- 
ments, in addition to changes in insulation and mechanisms of vascular control, largely preclude an adaptive role for body size. However, as stated by Mayr (1963: 321), "Multiple solutions for biological needs are the general rule in evolution. Selective advantages are independent and strictly additive. The fact that a thicker fur or denser plumage reduces heat loss does not eliminate completely the selective advantage of an improved body surface/volume ratio." The same logic applies to physiological explanations of Bergmann's Rule that are based on the scaling relationship between body mass and total metabolic rate.

Causal explanations for the underlying basis of Bergmann's Rule have traditionally invoked the adaptive significance of body size in connection with temperature regulation or conservation of metabolic water (Hamilton, 1961; Mayr, 1963; Brown \& Lee, 1969; Power, 1969; James, 1970). An alternative hypothesis is that geographic patterns of size variation primarily reflect selection for fasting endurance during episodic periods of food scarcity in seasonal environments (Boyce, 1979; Lindstedt \& Boyce, 1985; Millar \& Hickling, 1990). In contrast to explanations based on surface/volume ratios, the fasting endurance hypothesis is based on a relationship between starvation time and body mass that is derived from total units, and therefore can be interpreted with respect to both total and mass-specific rates of metabolism (McNab, 1999). This hypothesis has received correlative support from studies of intraspecific variation in temperate zone rodents (Boyce, 1978; Owen, 1989), marsupials (Quin et al., 1996), and passerine birds (Murphy, 1985). The fasting-endurance hypothesis deserves serious attention in nonmigratory tropical frugivores and nectarivores that rely on the sequential overlap of fruiting and flowering peaks in different plant species throughout the annual cycle. The latitudinal cline in body size of C. sphinx is consistent with each of the major adaptive hypotheses, due to parallel variation in multiple climatic factors across peninsular India. The increase in body size of $C$. sphinx parallels a latitudinal gradient of increasing minimum daily temperature, decreasing relative humidity, and increasing seasonality of temperature and precipitation. Each of the relevant climatic factors covary to such an extent that their independent effects cannot be readily discerned. A broader geographic scale of sampling may be required to elucidate the causal basis of clinal variation. Furthermore, calculating an index of seasonality that is biologically relevant to tropical frugivores would require information on the phenology of key food plants on a macrogeographic scale.

With regard to the multiple regression analysis, the explanatory power of the complete set of ecogeographic variables was comparable to that observed in previous studies of geographic variation in continental populations of vespertilionid bats (Burnett, 1983; Bogdanowicz, 1990). In North America, Eptesicus fuscus exhibits a progressive increase in size across a gradient of decreasing ambient temperature, in agreement with the classical form of Bergmann's Rule. In contrast to the pattern observed in Indian populations of C. sphinx, wing size of $E$. fuscus exhibited a proportional decrease across a gradient of increasing aridity. However, interpretation of this trend was complicated by the fact that patterns of variation in craniometric and external characters were not entirely concordant (Burnett, 1983). In the absence of data on body mass, it is not clear whether craniometric characters provide a meaningful index of overall structural size. Also consistent with Bergmann's Rule, Eurasian populations of Myotis daubentoni exhibit a progressive increase in size (as indexed by craniometric and dental characters) across a gradient of decreasing temperature and increasing precipitation. Negative correlations between ambient temperature and size (or positive correlations between latitude and size) have been reported for several microchiropteran bat species (Findley \& Jones, 1967; Stebbings, 1973; Bogan, 1975; Owen et al., 1984; Tidemann, 1986; Hand \& York, 1990), though exceptions exist (Strelkov, 1972). Still other species exhibit complex patterns of geographic variation that defy a clear explanation in terms of climatic adaptation (Findley \& Traut, 1970; Nagorsen \& Tamsitt, 1981; McLellan, 1984; Kitchener \& Caputi, 1985). In the Lesser Sunda Islands of the Malay Archipelago, Cynopterus nusatenggara (Pteropodidae) and Hipposideros diadema (Hipposideridae) exhibit longitudinal clines of increasing size across a west-to-east gradient of increasing aridity and climatic severity (Kitchener et al., 1992; Kitchener \& Maharadatunkamsi, 1996). These same patterns of geographic size variation are paralleled by a number of co-distributed Indo-Australian mammals (Kitchener \& Suyanto, 1996), which strongly suggests a common evolutionary response to a shared set of spatially varying ecogeographic factors. The generality of clinal variation in body size of Indian mammals and birds remains to be investigated, although information compiled by Ali \& Ripley (1980) indicates that many nonmigratory birds of the Indian plains (including pigeons, parakeets, trogons, mynas, and bulbuls) exhibit a south-to-north trend of increasing size. The remarkably steep cline in body size of Cynopterus sphinx suggests that variation of equal or greater magnitude can be expected in other small-bodied homeotherms that are distributed across the same climatic gradients.

Geographic variation in body size may also reflect the influence of character displacement in areas of range overlap between ecologically similar species that com- 
pete for the same food resources (Grant, 1965; Brown, 1975; Heaney, 1978). Of the four other species of frugivorous bats that occur in peninsular India, only Rousettus leschenaulti and Pteropus giganteus could reasonably be expected to represent close competitors of C. sphinx, and both species have equally cosmopolitan distributions (Bates \& Harrison, 1997). Cynopterus brachyotis (a smaller-bodied congener) and Latidens salimalii are largely restricted to tropical evergreen forest habitat in higher elevations of the Western Ghats (Storz et al., unpublished data; J. Koilraj, pers. comm.). More refined information on the ecological distribution, relative abundance, and degree of dietary overlap among avian and mammalian frugivores (Ganesh \& Davidar, 1999) are needed to assess whether competitive interactions have any significant role in determining body size variation of $C$. sphinx in peninsular India.

\section{Geographic Variation in Sexual Dimorphism}

Although patterns of size variation were highly concordant between the sexes, C. sphinx also exhibited a latitudinal cline in the magnitude and direction of sexual size dimorphism. Geographic variation in sexual dimorphism has been documented in several mammalian taxa, including pocket gophers (genus Thomomys; Patton \& Smith, 1992), North American weasels (genus Mustela; Ralls \& Harvey, 1985), and Australian sugar gliders (genus Petaurus; Quin et al., 1996). With regard to causal explanations for the pattern of sexual dimorphism in $C$. sphinx, Myers' (1978) hypothesis makes clear predictions about the nature of morphological differences between the sexes. Specifically, selection on females for reduced wing-loading should result in females having proportionally greater wing area relative to males. The hypothesis of Williams \& Findley (1979) provides an equally clear prediction about variation in sexual dimorphism in response to climatic variation; selection on females for enhanced thermal inertia should result in a greater degree of female-biased size dimorphism in colder environments. The pattern of sexual dimorphism in $C$. sphinx appears to support Myers' (1978) wing-loading hypothesis. In the southernmost localities, where the degree of female-biased size dimorphism was most pronounced, characters that exhibited the greatest size differential were skeletal elements of the hand-wing. It is unclear, however, why the female-biased size differential is negatively correlated with overall body size. The pattern of geographic variation in sexual dimorphism of C. sphinx is in direct contrast to the prediction of the Williams \& Findley (1979) hypothesis. If the adaptive value of increased female size is related to thermal homeostasis during pregnancy, the degree of female- biased dimorphism should be inversely correlated with mean minimum daily temperature. The opposite pattern was observed, as males were larger than females in the northernmost localities where minimum temperatures are lowest $\left(18.2-19.2^{\circ} \mathrm{C}\right)$. The hypothesis of Williams \& Findley (1979) was originally formulated in terms of the relationship between body size and the energetics of temperature regulation in vespertilionid bats. Perhaps this hypothesis is not generally applicable to pteropodid bats in tropical environments.

The increase in relative size of males in the northernmost localities may also reflect the pressure of sexual selection. Available evidence suggests that the degree of polygyny may be subject to a considerable degree of geographic variation in C. sphinx. Information on the mode of social organization and mating system is available for Pune (northern locality; Storz et al., 2000b) and Palayamkottai (southern locality; Storz et al., 2000a). In both localities, the clustering of breeding females in confined roosting spaces facilitates a male mating strategy of resource defense polygyny (Storz et al., 2000a,b). Comparative census data revealed striking differences between the two sites with regard to patterns of female dispersion during the postpartum estrus period. Compared to Palayamkottai, the mean number of breeding females per roost in Pune was 16.4-fold greater, the proportion of available roosts defended by territorial males was 5.8-fold greater, the overall level of female aggregation (as indicated by the variance/mean ratio of harem size) was 4.7 -fold greater, and the average harem sex ratio was 4.2-fold greater. Interpreting the harem sex ratio as an empirical measure of the potential for polygyny, the expected variance in male mating success (and concomitant opportunity for sexual selection) appears to be much higher in Pune than in Palayamkottai. Information on the mating system of C. sphinx from a greater number of localities and habitat types will be required to determine whether the degree of polygyny does in fact covary with the magnitude of male-biased size dimorphism.

\section{Acknowledgments}

For assistance in the field, we thank S. Isaac, J. Ronald, K. Emmanuel, N. Gopukumar Nair, V. Elangovan, J. Koilraj, and E. Rajan. For logistical support we thank G. Marimuthu, R. Subbaraj, G. Desai, K. N. More, D. N. Deobagkar, S. R. R. Reddy, S. L. Shinde, R. Patel, and the personnel at St. John's College, St. Xavier's College, Madurai Kamaraj University, Mysore University, Vaccine Institute of Belgaum, Shivaji University, and Pune University. For comments on the manuscript, we thank B. K. McNab, T. Kingston, C. J. Schneider, F. E. Wasserman, and two anonymous reviewers for the BJLS. Field expeditions by JFS and HRB in 1997-1998 were funded by a Research and Exploration Grant from the National 
Geographic Society. Additional funding was provided by grants to JFS from the National Science Foundation (Dissertation Improvement Grant DEB 97-01057), Sigma Xi, the American Society of Mammalogists, Bat Conservation International, and the Society for Integrative and Comparative Biology, and a grant to THK and JFS from the Lubee Foundation, Inc. JFS received additional support from the Albert R. and Alma Shadle Fellowship in Mammalogy during preparation of the manuscript.

\section{References}

Aldrich JW, James FC. 1991. Ecogeographic variation in the American robin Turdus migratorius. Auk 108: 230-249.

Ali S, Ripley SD. 1980. Handbook of the Birds of India and Pakistan (2nd edition). New Delhi: Oxford University Press.

Anthony ELP. 1988. Age determination in bats. In: Kunz $\mathrm{TH}$, ed. Ecological and Behavioral Methods for the Study of Bats. Washington DC: Smithsonian Institution Press, 47-58.

Balasingh J, Koilraj J, Kunz TH. 1995. Tent construction by the short-nosed fruit bat Cynopterus sphinx (Chiroptera: Pteropodidae) in southern India. Ethology 100: 210-229.

Bates PJJ, Harrison DL. 1997. Bats of the Indian Subcontinent. Sevenoaks, Kent: Harrison Zoological Museum.

Baumgardener GD, Kennedy ML. 1993. Morphometric variation in kangaroo rats (genus Dipodomys) and its relationship to selected abiotic variables. Journal of Mammalogy 74: 69-85.

Bergmann C. 1847. Uber die verhältnisse der warmeokonomie der thiere zu ihrer grösse. Göttinger Studien 3: 595-708.

Bhat HR, Kunz TH. 1995. Altered flower/fruit clusters of the kitul palm used as roosts by the short-nosed fruit bat, Cynopterus sphinx (Chiroptera: Pteropodidae). Journal of Zoology (London) 235: 597-604.

Bogan MA. 1975. Geographic variation in Myotis californicus in the southwestern United States and Mexico. United States Fish and Wildlife Service, Research Report 3: 1-31.

Bogdanowicz W. 1990. Geographic variation and taxonomy of Daubenton's bat, Myotis daubentoni, in Europe. Journal of Mammalogy 71: 205-218.

Boyce MS. 1978. Climatic variability and body size variation in the muskrats (Ondatra zibethicus) of North America. Oecologia 36: 1-19.

Boyce MS. 1979. Seasonality and patterns of natural selection for life histories. American Naturalist 114:569-583.

Brown JH. 1975. Geographical ecology of desert rodents. In: Cody ML, Diamond JM, eds. Ecology and Evolution of Communities. Cambridge: Harvard University Press, 775-787.

Brown JH, Lee AK. 1969. Bergmann's Rule and climatic adaptation in woodrats (Neotoma). Evolution 23: 329-338.

Burnett CD. 1983. Geographic and climatic correlates of morphological variation in Eptesicus fuscus. Journal of Mammalogy 64: 437-444.
Clutton-Brock TH, Harvey PH. 1983. The functional significance of variation in body size among mammals. In: Eisenberg JF, Kleiman DG, eds. Advances in the Study of Mammalian Behavior. Special Publication of the American Society of Mammalogists, 7, 632-663.

Dayan T, Simberloff D, Tchernov E, Yom-Tov Y. 1991. Calibrating the paleothermometer: climate, communities, and the evolution of size. Paleobiology 17: 189-199.

Findley JS, Jones C. 1967. Taxonomic relationships of bats of the species Myotis fortidens, M. lucifugus, and M. occultus. Journal of Mammalogy 48: 429-444.

Findley JS, Traut GL. 1970. Geographic variation in Pipistrellus hesperus. Journal of Mammalogy 51: 741-765.

Findley JS, Wilson DE. 1982. Ecological significance of chiropteran morphology. In: Kunz, TH, ed. Ecology of Bats. New York: Plenum Press, 243-260.

Freeman S, Jackson WM. 1990. Univariate metrics are not adequate to measure avian body size. Auk 107: 69-74.

Ganesh T, Davidar P. 1999. Fruit biomass and relative abundance of frugivores in a rainforest of southern Western Ghats, India. Journal of Tropical Ecology 15: 399-413.

Grant PR. 1965. The adaptive significance of size trends in island birds. Evolution 19: 355-367.

Grant PR, Abbott I, Schluter D, Curry RL, Abbott LK. 1985. Variation in the size and shape of Darwin's finches. Biological Journal of the Linnean Society 25: 1-39.

Graves GR. 1991. Bergmann's rule near the equator: Latitudinal clines in body size of an Andean passerine bird. Proceedings of the National Academy of Sciences, USA 88: 2322-2325.

Hamilton TH. 1958. Adaptive variation in the genus Vireo. Wilson Bulletin 70: 307-346.

Hamilton TH. 1961. The adaptive significances of intraspecific trends of variation in wing length and body size among bird species. Evolution 15: 180-195.

Hand S, York A. 1990. Morphological variation in the dentition and skull of the Australian ghost bat, Macroderma gigas (Microchiroptera: Megadermatidae). Australian Journal of Zoology 38: 263-286.

Handford P. 1983. Continental patterns of morphological variation in a South American sparrow. Evolution 37: 920-930.

Heaney LR. 1978. Island area and body size of insular mammals: evidence from the tricolor squirrel (Callosciurus prevosti) of south-east Asia. Evolution 32: 29-44.

James FC. 1970. Geographic size variation in birds and its relationship to climate. Ecology 51: 365-390.

Kitchener DJ, Caputi N. 1985. Systematic revision of Australian Scoteanax and Scotorepens (Chiroptera: Vespertilionidae), with remarks on relationships to other Nycticeiini. Record of the Western Australian Museum 12: 85-146.

Kitchener DJ Maharadatunkamsi 1991. Description of a new species of Cynopterus (Chiroptera: Pteropodidae) from Nusa Tenggara, Indonesia. Record of the Western Australian Museum 15: 307-363.

Kitchener DJ Maharadatunkamsi 1996. Geographic variation 
in morphology of Cynopterus nusatenggara (Chiroptera, Pteropodidae) in southeastern Indonesia, and description of two new subspecies. Mammalia 60: 255-276.

Kitchener DJ, Suyanto A. 1996. Intraspecific morphological variation among island populations of small mammals in southern Indonesia. In: Kitchener DJ, Suyanto A, eds. Proceedings of the First International Conference on Eastern Indonesian-Australian Vertebrate Fauna. Perth, Australia: Western Australian Museum, 7-13.

Kitchener DJ, How RA, Cooper N, Suyanto A. 1992. Hipposideros diadema (Chiroptera, Hipposideridae) in the Lesser Sunda Islands, Indonesia: taxonomy and geographic morphological variation. Record of the Western Australian Museum 16: 1-60.

Kunz TH. 1982. Roosting ecology of bats. In: Kunz TH, ed. Ecology of Bats. New York: Plenum Press, 1-55.

Kunz TH. 1987. Post-natal growth and energetics of suckling bats. In: Fenton MB, Racey P, Rayner JMV, eds. Recent Advances in the Study of Bats. Cambridge: Cambridge University Press, 395-420.

Lande R. 1980. Sexual dimorphism, sexual selection, and adaptation in polygenic characters. Evolution 34: 292-305.

Lindstedt SL, Boyce MS. 1985. Seasonality, fasting endurance, and body size in mammals. The American Naturalist 125: 873-878.

Lindstedt SL, Swain SD. 1988. Body size as a constraint of design and function. In: Boyce MS, ed. Evolution of life histories of mammals. New Haven: Yale University Press, 93-105.

Mani MS. 1974a. Limiting factors. In: Mani MS, ed. Ecology and Biogeography in India. The Hague, Netherlands: Dr. W. Junk Publishers, 135-158.

Mani MS. 1974b. The flora. In: Mani MS, ed. Ecology and Biogeography in India. The Hague, Netherlands: Dr. W. Junk Publishers, 159-177.

Mayr E. 1944. The birds of Timor and Sumba. Bulletin of the American Museum of Natural History 83: 123-194.

Mayr E. 1956. Geographical character gradients and climatic adaptation. Evolution 10: 105-108.

Mayr E. 1963. Animal Species and Evolution. Cambridge: Belknap Press, Harvard University Press.

Mayr E, Vaurie C. 1948. Evolution in the family Dicruridae (birds). Evolution 2: 238-265.

McCracken GF, Bradbury JW. 1981. Social organization and kinship in the polygynous bat, Phyllostomus hastatus. Behavioral Ecology and Sociobiology 8: 11-34.

McLellan LJ. 1984. A morphometric analysis of Carollia (Chiroptera, Phyllostomidae). American Museum Novitates 2791: 1-35.

McNab BK. 1971. On the ecological significance of Bergmann's Rule. Ecology 52: 845-854.

McNab BK. 1982. Evolutionary alternatives in the physiological ecology of bats. In: Kunz TH, ed. Ecology of Bats. New York: Plenum Press, 151-200.

McNab BK. 1989. Temperature regulation and rate of metab- olism in three Bornean bats. Journal of Mammalogy 70: 153-161.

McNab BK. 1999. On the comparative ecological and evolutionary significance of total and mass-specific rates of metabolism. Physiological and Biochemical Zoology 72: 642-644.

McNab BK, Bonaccorso FJ. 1995. The energetics of pteropodid bats. In: Racey PA, Swift SM, eds. Ecology, Evolution and Behavior of Bats. Oxford: Oxford University Press, $111-122$.

Millar JS, Hickling GJ. 1990. Fasting endurance and the evolution of mammalian body size. Functional Ecology 4: 5-12.

Moreau RE. 1957. Variation in the western Zosteropidae (Aves). Bulletin of the British Museum (Natural History), Zoology 4: 311-433.

Mosimann JE, James FC. 1979. New statistical methods for allometry with application to Florida redwinged blackbirds. Evolution 33: 444-459.

Murphy EC. 1985. Bergmann's Rule, seasonality, and geographic variation in body size of house sparrows. Evolution 39: 1327-1334.

Myers P. 1978. Sexual dimorphism in size of vespertilionid bats. The American Naturalist 112: 701-711.

Nagorsen D, Tamsitt JR. 1981. Systematics of Anoura cultrata, Anoura brevirostrum, and Anoura werckleae. Journal of Mammalogy 62: 82-100.

Ochoa-Acuña H, Kunz TH. 1999. Thermoregulatory behavior in the small island flying fox, Pteropus hypomelanus (Chiroptera: Pteropodidae). Journal of Thermal Biology 24: 15-20.

Owen JG. 1989. Population and geographic variation of Peromyscus leucopus in relation to climatic factors. Journal of Mammalogy 70: 98-109.

Owen JG, Schmidley DJ, Davis WB. 1984. A morphometric analysis of Carollia (Chiroptera, Glossophaginae) from Middle America. Mammalia 48: 85-93.

Patton JL, Brylski PV. 1987. Pocket gophers in alfalfa fields: causes and consequences of habitat-related body size variation. The American Naturalist 130: 493-506.

Patton JL, Smith MF. 1992. The evolutionary dynamics of the pocket gopher Thomomys bottae, with emphasis on California populations. University of California Publications in Zoology 123: 1-161.

Piersma T, Davidson NC. 1991. Confusions of mass and size. Auk 108: 441-443.

Power DM. 1969. Evolutionary implications of wing and size variation in the red-winged blackbird in relation to geographic and climatic factors: a multiple regression analysis. Systematic Zoology 18: 363-373.

Price TD. 1984. The evolution of sexual size dimorphism in Darwin's finches. The American Naturalist 123: 500-518.

Quin DG, Smith AP, Norton TW. 1996. Ecogeographic variation in size and sexual dimorphism in sugar gliders and squirrel gliders (Marsupialia: Petauridae). Australian Journal of Zoology 44: 19-45. 
Ralls K. 1977. Sexual dimorphism in mammals: avian models and unanswered questions. The American Naturalist 111: 917-938.

Ralls K, Harvey PH. 1985. Geographic variation in size and sexual dimorphism of North American weasels. Biological Journal of the Linnean Society 25: 119-167.

Ramdas LA. 1974. Weather and climatic patterns. In: Mani MS, ed. Ecology and Biogeography in India. The Hague, Netherlands: Dr. W. Junk Publishers, 99-134.

Ripley SD. 1950. Birds from Nepal, 1947-1949. Journal of the Bombay Natural History Society 49: 355-417.

Rising JD, Somers KM. 1989. The measurement of overall body size in birds. Auk 106: 666-674.

Ruedas LA, Demboski JR, Sison RV. 1994. Morphological and ecological variation in Otopteropus cartilagonodus Kock, 1969 (Mammalia: Chiroptera: Pteropodidae) from Luzon, Phillippines. Proceedings of the Biological Society of Washington 107: 1-16.

Scholander PF. 1955. Evolution of climatic adaptation in homeotherms. Evolution 9: 15-26.

Searcy WA. 1980. Optimum body sizes at different ambient temperatures: an energetics explanation of Bergmann's rule. Journal of Theoretical Biology 83: 579-593.

Slowtow R, Goodfriend W. 1996. Ecogeographic variation in body size and shape of Cape sparrows (Passer melanurus) in southern Africa. Journal of Zoology (London) 238: 279-286.

Smith FA, Betancourt JL, Brown JH. 1995. Evolution of body size in the woodrat over the past 25,000 years of climatic change. Science 270: 2012-2014.

Sokal RR, Rohlf FJ. 1995. Biometry. New York: W.H. Freeman and Company.

Stebbings RE. 1973. Size clines in the bat Pipistrellus pipistrellus related to climatic factors. Periodicum Biologorum 75: 189-194.

Storz JF, Kunz TH. Cynopterus sphinx. Mammalian Species 613: 1-8.

Storz JF, Balasingh J, Nathan PT, Emmanuel K, Kunz TH. 2000a. Dispersion and site fidelity in a tent-roosting population of the short-nosed fruit bat (Cynopterus sphinx) in southern India. Journal of Tropical Ecology 16: 117-131.

Storz JF, Bhat HR, Kunz TH. 2000b. Social structure of a polygnous tent-making bat, Cynopterus sphinx (Megachiroptera). Journal of Zoology (London) 251: 151-165.

Straney DO, Patton JL. 1980. Phylogenetic and environmental determinants of geographic variation of the pocket mouse Perognathus goldmani Osgood. Evolution 34: 888-903.
Strelkov PP. 1972. Myotis blythi (Tomes, 1857): distribution, geographical variability and differences from Myotis myotis (Borkhausen, 1797). Acta Theriologica 17: 355-380.

Subramanyam K, Nayar MP. 1974. Vegetation and phytogeography of the Western Ghats. In: Mani MS. Ecology and Biogeography in India. The Hague, Netherlands: Dr. W. Junk Publishers, 178-196.

Sullivan RM, Best TL. 1997. Effects of environment on phenotypic variation and sexual dimorphism in Dipodomys simulans (Rodentia: Heteromyidae). Journal of Mammalogy 78: 798-810.

Tidemann CR. 1986. Morphological variation in Australian and island populations of Gould's wattled bat, Chalinolobus gouldii (Gray) (Chiroptera: Vespertilionidae). Australian Journal of Zoology 34: 503-514.

Traylor MA. 1950. Altitudinal variation in Bolivian birds. Condor 52: 123-126.

Weigl PD, Sherman LJ, Williams AI, Steele MA, Weaver DS. 1998. Geographic variation in the fox squirrel (Sciurus niger): consideration of size clines, habitat vegetation, food habits, and historical biogeography. In: Steele MA, Merritt JF, Zegers DA, eds. Ecology and Evolutionary Biology of Tree Squirrels. Martinsville, Virginia: Virginia Museum of Natural History, 171-184.

Williams DF, Findley JS. 1979. Sexual size dimorphism in vespertilionid bats. American Midland Naturalist 102: 113-126.

Willig MR, Hollander RR. 1995. Secondary sexual dimorphism and phylogenetic constraints in bats: a multivariate approach. Journal of Mammalogy 76: 981-992.

Wooler RD, Saunders DA, Bradley JS, de Rebeira CP. 1985. Geographical variation in size of an Australian honeyeater (Aves: Meliphagidae): an example of Bergmann's rule. Biological Journal of the Linnean Society 25: 355-363.

Yom-Tov Y, Nix H. 1986. Climatological correlates for body size of five species of Australian mammals. Biological Journal of the Linnean Society 29: 245-262.

Zeveloff SI, Boyce MS. 1988. Body size patterns in North American mammal faunas. In: Boyce MS, ed. Evolution of life histories of mammals. New Haven: Yale University Press, 123-146.

Zink RM, Remsen JV. 1986. Evolutionary processes and patterns of geographic variation in birds. In: Johnston RF, ed. Current Ornithology, Vol. 4. New York: Plenum Press, 1-69. 